\title{
Polímeros: Novos Rumos para o Futuro
}

Em um mundo cheio de constantes mudanças sociais e econômicas e de avanços científicos e tecnológicos, torna-se imprescindível a definição de que caminhos tomar e em qual direção para esse futuro que está muito mais próximo do que imaginamos: o terceiro milênio. Nesse sentido, a revista "Polímeros: Ciência e Tecnologia" apresenta em sua seção editorial duas matérias onde são discutidos vários aspectos da área de plásticos e borrachas do país, bem como os próximos passos a dar.

Os dados apresentados sobre o setor de plásticos e borrachas do país, cujo faturamento global atinge os 18 bilhões de dólares, demonstram a relevância deste que é um dos setores que mais cresce no Brasil. O Estado de São Paulo, por exemplo, responsável por quase $60 \%$ desse valor, conta com aproximadamente 4.000 empresas atuando no setor de polímeros, gerando cerca de 200.000 empregos diretos. Por outro lado, é clara a pequena disponibilidade de profissionais especializados para o setor e a necessidade de investimentos, tanto em recursos humanos como em Pesquisa e Desenvolvimento. Está também abaixo do mínimo necessário o número de cursos oferecidos aos profissionais das empresas, para que ocorra a reciclagem e a atualização dos conhecimentos.

Em resposta a essa situação, a Secretaria de Ciência, Tecnologia e Desenvolvimento do Governo do Estado de São Paulo está estabelecendo uma política tecnológica para o setor de plásticos e borrachas, cujo planejamento estratégico e ações básicas recomendados são expostos aqui de forma sucinta.

Outros aspectos importantes sobre a modernização tecnológica no setor de transformação de plásticos também serão apresentados nesta edição, para que o empresariado nacional possa enfrentar em igualdade de condições a competição internacional. Nesse sentido, o Centro de Formação e Treinamento da ABPol tem um papel de destaque, não apenas pelo oferecimento, em 1997, de 13 cursos abertos, como pela importante interação que vem mantendo com a SPE (Society of Plastics Engineers) e INP (Instituto Nacional do Plástico), iniciativa que está viabilizando o oferecimento de 4 seminários com especialistas internacionais.

Nesta sociedade em constante competição e onde somente os mais fortes resistem, lembramos o exemplo dos plásticos de maior resistência mecânica, como os reforçados com fibras. O reforço é o empenho e a participação de todos, essenciais não apenas para o sucesso desta Revista, como do setor de plásticos do País. 